See Article page 118.

\section{Commentary: Reoperative} transapical transcatheter aortic valve implantation for a degenerated biological valve: An approach with caution or a mission impossible?

Thomas Theologou, MD, FRCSC-Th, ${ }^{\mathrm{a}}$ and Tom C. Nguyen, $\mathrm{MD}^{\mathrm{b}}$

We read with great interest the case report by Ricciardi and colleagues ${ }^{1}$ describing reoperative transapical (TA) transcatheter aortic valve implantation (TAVI) for a degenerated biological valve in a high-risk patient. The authors describe a 73-year-old patient with severe peripheral vascular disease and inadequate iliofemoral vessels. The patient initially underwent a TA TAVR using a 23-mm Edwards SAPIEN XT prosthesis but presented approximately 7 years later with structural valve deterioration. The authors subsequently proceeded with a redo TATAVR and concluded that this is a viable approach in frail patients with failed transcatheter valves, although further studies are needed.

We should congratulate the authors for the success of their case, but we would like to emphasize that redo TA TAVR should be approached with caution. The authors did provide practical and thoughtful pearls and pitfalls, including a step-by-step structured methodology to safely identify the left ventricular apex using transthoracic echocardiography, and the suggestion to directly enter the cardiac apex from the previous scar, leaving pericardium and

From the ${ }^{\mathrm{a} D e p a r t m e n t}$ of Cardiac Surgery, Cardiocentro Ticino, Lugano, Switzerland; and ${ }^{\mathrm{b}}$ Department of Cardiothoracic and Vascular Surgery, University of Texas Health Science Center Houston, McGovern Medical School, Memorial Hermann Hospital-Heart and Vascular Institute, Houston, Tex.

Disclosures: The authors reported no conflicts of interest.

The Journal policy requires editors and reviewers to disclose conflicts of interest and to decline handling or reviewing manuscripts for which they may have a conflict of interest. The editors and reviewers of this article have no conflicts of interest.

Received for publication Oct 19, 2020; revisions received Oct 19, 2020; accepted for publication Oct 20, 2020; available ahead of print Oct 22, 2020.

Address for reprints: Tom C. Nguyen, MD, Memorial Hermann, University of Texas Health Science Center at Houston, 6400 Fannin St, Suite 2850, Houston, TX 77030 (E-mail: tom.c.nguyen@gmail.com).

JTCVS Techniques 2020;4:121

2666-2507

Copyright (C) 2020 The Authors. Published by Elsevier Inc. on behalf of The American Association for Thoracic Surgery. This is an open access article under the CC BY-NCND license (http://creativecommons.org/licenses/by-nc-nd/4.0/).

https://doi.org/10.1016/j.xjtc.2020.10.025
Check for updates

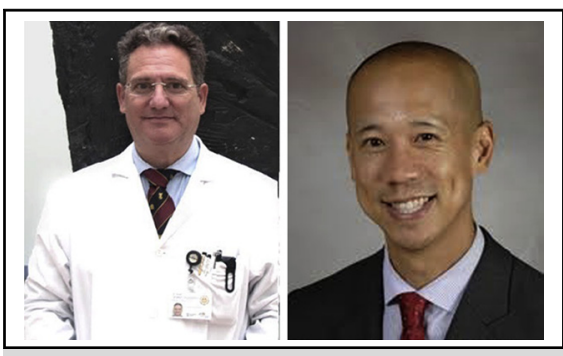

Thomas Theologou, MD, FRCSC-Th, and Tom C. Nguyen, MD

CENTRAL MESSAGE

Reoperative transapical transcatheter aortic valve implantation for a degenerated biological valve is feasible but should be proceeded with caution, as outcomes could be disastrous.

previous Teflon pledgets intact. By leaving adhesions and previous Teflon pledgets on the apex, this provides a support structure to facilitate closing the puncture site at the end of the procedure. Looking at the literature, other authors, on the contrary, were removing the Teflon pledgets. ${ }^{2}$

Several points are noteworthy when considering redo TA TAVR, including: (1) the patient's access complexity, (2) the balance between risks and benefits of performing this procedure, and careful informed consent of the patient and his/her family (3) the previous experience of the surgeon and her/his team in similar cases, and (4) the choice of a correct size of the transcatheter valve to prevent premature valve degeneration.

Finally, further investigating this redo TA TAVR with a randomized control trial or an observational study may present ethical and practical issues. These cases are relatively rare and may be difficult to recruit patients for the study. The risk of aortic or left ventricular rupture is tangible and may not justify randomization. This provides a oneway ticket with no return journey, as even if an emergency surgery could be performed after a complicated redo TA TAVI, it will inevitably portend an adverse outcome.

\section{References}

1. Ricciardi G, Cavallotti L, Alamanni F, Roberto M. Reoperative transapical transcatheter aortic valve implantation for a degenerated biological valve. J Thorac Cardiovasc Surg Tech. 2020;4:118-20.

2. Kiefer P, Seeburger J, Chu MW, Ender J, Vollroth M, Noack T, et al. Re-operative transapical aortic valve implantation for early structural valve deterioration of SAPIEN XT valve. Ann Thorac Surg. 2013;95:2169-70. 